\section{INTEGRATED \\ NEMATODE \\ MANAGEMENT}

State-of-the-Art and

Visions for the Future

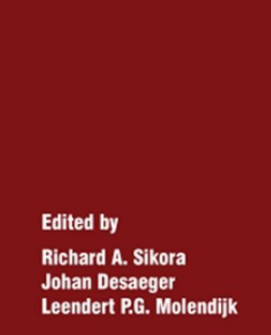

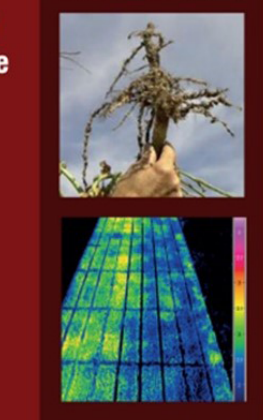

\title{
R.A. Sikora, J. Desaeger and L.P.G. Molendijk, Integrated Nematode Management, ISBN-13: 9781789247541 (Hardback), 9781789247558 (ePDF), 9781789247565 (ePub): Open Access, https://dx.doi. org/10.1079/9781789247541.0000
}

Reviewed by Hari S. Gaur, Dean, School of Agricultural Sciences, Sharda University, Greater Noida, India; Former Vice-Chancellor, Sardar Vallabhbhai University of Agriculture and Technology, Meerut, India; Email: Email: hs.gaur@sharda.ac.in, sgaur8@gmail.com

https://dx.doi.org/10.17582/journal.pjn/2021.39.2.158.159

The book entitled, Integrated Nematode Management: State-of-the-art and Visions for the Future, is a truly unique and valuable publication different from the usual text and reference books. It comprises of the collective wisdom and experience of 82 highly experienced nematologists drawn from 19 countries in five continents. There are 65 crisp and concise chapters that outline the economic importance of most of the nematode problems limiting the production of major food, feed and industrial crops. The management strategies currently recommended and practiced are described for economically important nematodes of the world, their limitations are expressed and state of the art strategies for reducing crop losses are stated. Global case studies to illustrate the effect of nematodes in field have been described. Imminent future challenges in the motor disease problems in the wake of global climate change and cropping systems I've been highlighted. The excellent forewords by Dieter Hofer and others of Syngenta Crop Protection and Larry Duncan of the University of Florida have highlighted the seriousness of existing and emerging nematode problems across the world; the challenges faced especially by smallholder farmers and the limitations of the existing limited management technologies. Attention has been drawn to the emerging novel technologies like the computer based decision support systems, drone and satellite based imageries for precision farming and molecular biology based diagnostics and induction of genetic resistance in crops against nematodes. The necessity of translating modern technologies into adoptable economically viable technologies under field situation has been expressed in most chapters.

The opening chapter by the editors introduces the principles of integrated nematode management (INM), the future challenges and opportunities. The following eight chapters cover the root-lesion and cereal cyst nematodes in wheat; root-lesion, root-knot and other nematodes affecting maize and the rootknot and rice-root nematodes damaging rice. Next 
chapter discusses the root-lesion nematode damage in sugarcane. There are four chapters on the root-knot, reniform, root-lesion and lance nematodes affecting cotton. Five chapters address the nematode pests of soybean, especially root-knot, reniform, root-lesion and soybean cyst nematodes in Brazil, China and the USA. Two of the chapters cover chickpea, broadbeans and some other legumes. One chapter covers the Ditylenchus africanus problem while another talks about Meloidogyne arenaria affecting groundnuts. Anybody dealing with horticultural crops will find a treasure in at least 11 chapters covering various nematode problems of fruits, nuts and coffee. As many as eight chapters are devoted to nematode problems of various vegetable crops. The menace of nematodes under plastic mulched beds, polyhouses and protected cultivation systems, considered paradise for nematodes, has received good attention.

Overall, it is seen that many nematode problems are serious limitations in production, quality and profitability of almost all kinds of crops that are economically important to humans. Nematodes themselves cause serious losses and fungal, bacterial diseases complexes induced and viruses transmitted by nematodes can cause devastations. The various cultural practices of prevention, soil tillage, water management, soil solarization, biofumigation, organic amendments, crop rotation, selection of resistant/tolerant/ antagonistic crops, some fungal and bacterial bio-control agents and scarcely available nematicides are the practices recommended all over the world but followed by only some farmers over the past 30-40 years. The poor farmers-awareness, low extension activity, dwindling number of applied nematologists, small land-holdings and inadequate resources prevent large scale adoption of the currently available INM technologies. Decreasing research funding for applied nematology is also obstructing improvement, validation and adoption of new technologies.

As many as seven chapters are devoted to Globodera spp., Meloidogyne spp., Pratylenchus penetrans, Ditylenchus destructor and the virus transmitting Trichodorus spp. All affecting potato. The problems of root-knot nematodes on sweet potato in Australia, Scutellonema spp. on yams in West Africa and rootknot nematodes damaging cassava are well covered in three separate chapters. The Ditylenchus dipsaci and Heterodera schachtii on sugarbeet are also discussed in two chapters.
The following seven chapters 56-62 concisely describe and discuss the emerging technologies, such as the soil biome analysis for diagnosis of suppressive or supportive soils; genome editing, including CRISPR-Cas, for induction of genetic resistance/ tolerance; remote-sensing, precision farming and decision support systems giving internationally available relevant digital resources. The development of novel nematicides and production microbial agents are very well described. The chapter 63 especially discusses the limitations and possible strategies for small-holder farmers. The next very interesting chapter by Sikora et al. highlights 'unpredictability' of INM considering the likely impacts of global climate changes that will impact nematodes, crops and cropping systems worldwide. They have tried to draw inferences from all the preceding chapters and their own wisdom to guide in designing new short-term, medium and long term strategies for practical nematode management. In the final Chapter 65 the editors have derived important conclusions, described their outlook and given a nice summary of the prevailing strategies upto the 2020 and foresee highly plausible strategies for 2020-50. There is an elaborate index at the end for quick reference. The book is illustrated with many very high quality representative colour photographs, figures and data.

In the short crisp chapters the authors, upon the advice of the team of editors, have avoided routine exhaustive citation approach and have described their own and others' experience in specific problems in particular regions. Much of the descriptions may also be found useful in other parts of the world. They have expressed their own judgment and opinions and come out with realistic and plausible approaches unlike prevalent large review articles. This book, as envisaged, is a perfect guide and handbook to applied plant protection practitioners, a reference for researchers, and an excellent textbook for teachers and students of nematology/ entomology/ plant pathology across the world.

The stupendous effort of Prof. Richard Sikora and his team of editors and the publishers, CABI International, deserve much admiration in bringing out this monumental book. Syngenta Crop Protection have done a great service by supporting the Open-Access publication of this valuable book free, easy and wide access globally. 